\title{
Receptor-associated prorenin system contributes to development of inflammation and angiogenesis in proliferative diabetic retinopathy
}

\author{
Atsuhiro Kanda* (iD and Susumu Ishida
}

\begin{abstract}
The renin-angiotensin system (RAS) plays a potential role in the development of end-organ damage, and tissue RAS activation has been suggested as a risk factor of several diseases including diabetes. So far, using animal disease models, we have shown molecular mechanisms, in which tissue RAS stimulates retinal angiogenesis, and the critical roles of (pro)renin receptor [(P)RR] in retinal RAS activation and its concurrent intracellular signal transduction, referred to as the receptor-associated prorenin system (RAPS). Moreover, we recently reported that the protein levels of prorenin and soluble (P)RR increased in the vitreous fluids obtained from patients with proliferative diabetic retinopathy (PDR), suggesting the association of (P)RR with vascular endothelial growth factor (VEGF)-driven angiogenic activity in human PDR, and also showed a close relationship between the vitreous renin activity and VEGF-induced pathogenesis of diabetic retinopathy. Our data using animal disease models and human clinical samples suggest that both vitreous RAS and retinal RAPS play critical roles in the molecular pathogenesis of diabetic retinopathy.
\end{abstract}

Keywords: Receptor-associated prorenin system, Renin-angiotensin system, Angiotensin II type 1 receptor, (Pro) renin receptor

Abbreviations: (P)RR, (Pro)renin receptor; ACE, Angiotensin-converting enzyme; AGT, Angiotensinogen; Ang, Angiotensin; AT1R, Angiotensin II type 1 receptor; DR, Diabetic retinopathy; ERK, Extracellular signal-regulated kinase; NF-kB, Nuclear factor-kB; PDR, Proliferative diabetic retinopathy; RAPS, Receptor-associated prorenin system; RAS, Renin-angiotensin system; VEGF, Vascular endothelial growth factor

\section{Background}

Diabetic retinopathy (DR) is one of the severe complications of diabetes and leading cause of severe vision loss and blindness when it progresses to the stage of proliferative DR (PDR) characterized by fibrovascular proliferation. Fibrovascular tissue develops by the extension of retinal angiogenesis into the vitreous cavity, and formation of the fibrovascular tissue results in severe complications, such as tractional retinal detachment and vitreous hemorrhage. Several growth factors and cytokines are involved in the molecular pathogenesis of

\footnotetext{
*Correspondence: kanda@med.hokudai.ac.jp

Laboratory of Ocular Cell Biology and Visual Science, Department of Ophthalmology, Hokkaido University Graduate School of Medicine, N-15, W-7, Kita-ku, Sapporo, Hokkaido 060-8638, Japan

diabetic retinopathy; however, vascular endothelial growth factor (VEGF) has been considered as the major angiogenic and proinflammatory factor in PDR [1-3]. VEGF plays important roles in normal physiology such as in embryogenesis, endometrial maturation, and wound healing. However, it also causes profound pathogenesis complicating diabetes and cancer. Tumor growth requires new vessel formation, which is driven predominantly by VEGF, the most potent angiogenic factor and the principal target for anti-angiogenic therapy [4]. We previously revealed a significant contribution of VEGF165 isoform to angiogenic activity in PDR, showing that fibrovascular tissues co-expressing VEGF receptor (VEGFR)-2 and neuropilin (NRP) 1, the specific receptor for VEGF165, were highly vascularized [5-7]. 
VEGF165 were shown to increase the expression of adhesion molecules and subsequently stimulates leukocyte infiltration leading to the development of retinal angiogenesis [5-7].

The renin-angiotensin system (RAS), a known important controller of systemic blood pressure (circulatory RAS), plays distinct roles in inflammation and pathological vascular conditions in organs including the brain, eye, heart, liver, and kidney (tissue RAS) [8]. Tissue RAS acts in a paracrine fashion and regulates various biological and pathological events such as cell signaling, apoptosis, proliferation, angiogenesis, immune responses, and extracellular matrix formation [9-11]. In this review, we focus on the relationship between diabetic retinopathy and tissue RAS and suggest a novel concept for the molecular pathogenesis of tissue RAS in the vitreous, referred to as "vitreous RAS."

\section{Vitreous renin-angiotensin system and retinal receptor-associated prorenin system in diabetic retinopathy}

Several types of organ damage are known to result from activation of tissue RAS. As concerns its relationship with the eye, pharmacological blockade of angiotensin-converting enzyme (ACE) or angiotensin II type 1 receptor (AT1R) resulted in beneficial effects on the incidence and progression of DR in several clinical trials including the EUCLID study, DIRECT-Prevent 1, DIRECT-Protect 1, DIRECT-Protect 2, and the RAS study [12-15]. We unraveled the molecular mechanisms in which tissue RAS causes retinal inflammation and angiogenesis in the murine model of endotoxininduced uveitis, strepotozotocin-induced diabetes, and laser-induced choroidal neovascularization [16-18] and the critical role of (pro)renin receptor $[(\mathrm{P}) \mathrm{RR}]$ in retinal RAS activation [19-22]. Tissue RAS is initiated by prorenin binding with (P)RR to acquire renin activity, which also causes RAS-independent signal transduction in cells bearing (P)RR. Prorenin binding to (P)RR causes renin activity through the conformational change of prorenin (non-proteolytic activation of prorenin causing tissue RAS) instead of the conventional proteolysis of the prorenin prosegment by processing enzymes (proteolytic activation of prorenin causing circulatory RAS). In addition to tissue RAS activation, prorenin binding to (P)RR activates RAS-independent signal transduction via mitogen-activated protein kinases including extracellular signal-regulated kinase (ERK) $1 / 2$ pathway, which has been shown to contribute to organ damage. (P)RR can bind to both prorenin and renin, but the binding affinity of prorenin is much higher than that of renin [23]. The (P)RR-mediated dual activation of tissue RAS and RAS-independent signaling pathways, referred to as the receptor-associated prorenin system (RAPS), was shown to be involved in the molecular pathogenesis of ocular disorders including retinal inflammation and choroidal neovascularization $[20,21,24]$, both of which are due to the upregulated expression of VEGF in the downstream of retinal and choroidal RAPS, respectively.

Remarkably, (P)RR was reported to undergo cleavage by proteases to generate a soluble form of $(\mathrm{P}) \mathrm{RR}[\mathrm{s}(\mathrm{P}) \mathrm{RR}]$, whereas it still has a capability for non-proteolytic activation of prorenin, causing the conversion of angiotensinogen (AGT) to angiotensin I (Ang I) in vitro [25]. We have shown that $\mathrm{s}(\mathrm{P}) \mathrm{RR}$, prorenin, activated prorenin, and VEGF protein levels together with renin activity levels in vitreous fluids were significantly higher in PDR eyes compared to non-diabetic controls [26, 27]. Increased protein levels of $s(\mathrm{P}) \mathrm{RR}$ in PDR eyes, released from neovascular endothelial cells in fibrovascular tissues, were significantly correlated with vitreous prorenin, activated prorenin, and VEGF protein levels and the vascular density of fibrovascular tissues [26]. Interestingly, renin activity levels also significantly correlated with the vitreous protein levels of $s(P) R R$, prorenin, activated prorenin, and VEGF [27]. These data indicate that the vitreous renin activity stems from $s(\mathrm{P}) \mathrm{RR}$-mediated non-proteolytic activation of prorenin, suggesting the significant role of (P)RR in the pathogenesis of PDR. Indeed, (P)RR and RAS components were expressed in diabetic fibrovascular tissues, human retinal cell lines, and normal ocular tissues [26, 28-30], and the vitreous levels of prorenin and angiotensin II (Ang II) were shown to be elevated in PDR eyes [31-34]. Furthermore, a close link between the vitreous renin activity and VEGF protein levels validates our concept of vitreous RAS that contributes to the angiogenic activity of DR. Consequently, in concert with vitreous RAS due to $s(P) R R$ (Fig. 1a) [27], retinal RAPS due to membrane-type (i.e., full-length) (P)RR [26] (Fig. 1b) is thought to regulate VEGF expression in DR. Moreover, we have recently shown that RAPS is involved in the molecular pathogenesis of organ damage, such as inflammation, angiogenesis, and fibrosis, including conjunctival lymphoma [28] and other ocular disorders (under review).

Although we have shown the significant role of (P)RR signaling via ERK $[21,26]$ as well as AT1R signaling via nuclear factor (NF)-kB [16] in the upregulation of VEGF expression, it is difficult to determine the ratio of involvement with the angiogenic activity in human PDR. Cleavage enzymes for processing full-length (P)RR to $s(\mathrm{P}) \mathrm{RR}$ include the proprotein convertase furin [35] and ADAM (a disintegrin and metalloproteinase) 19 [36], both of which proved to be present in endothelial cells in the fibrovascular tissue in PDR [26]. Gene expression and enzymatic activity of these proteases in the neovascular endothelial cells are likely to define the contribution ratio between vitreous RAS and retinal RAPS. Investigation into the biochemical regulation of furin and ADAM19 is required in the future to further elucidate (P)RR-related molecular pathogenesis of diabetic retinopathy. 


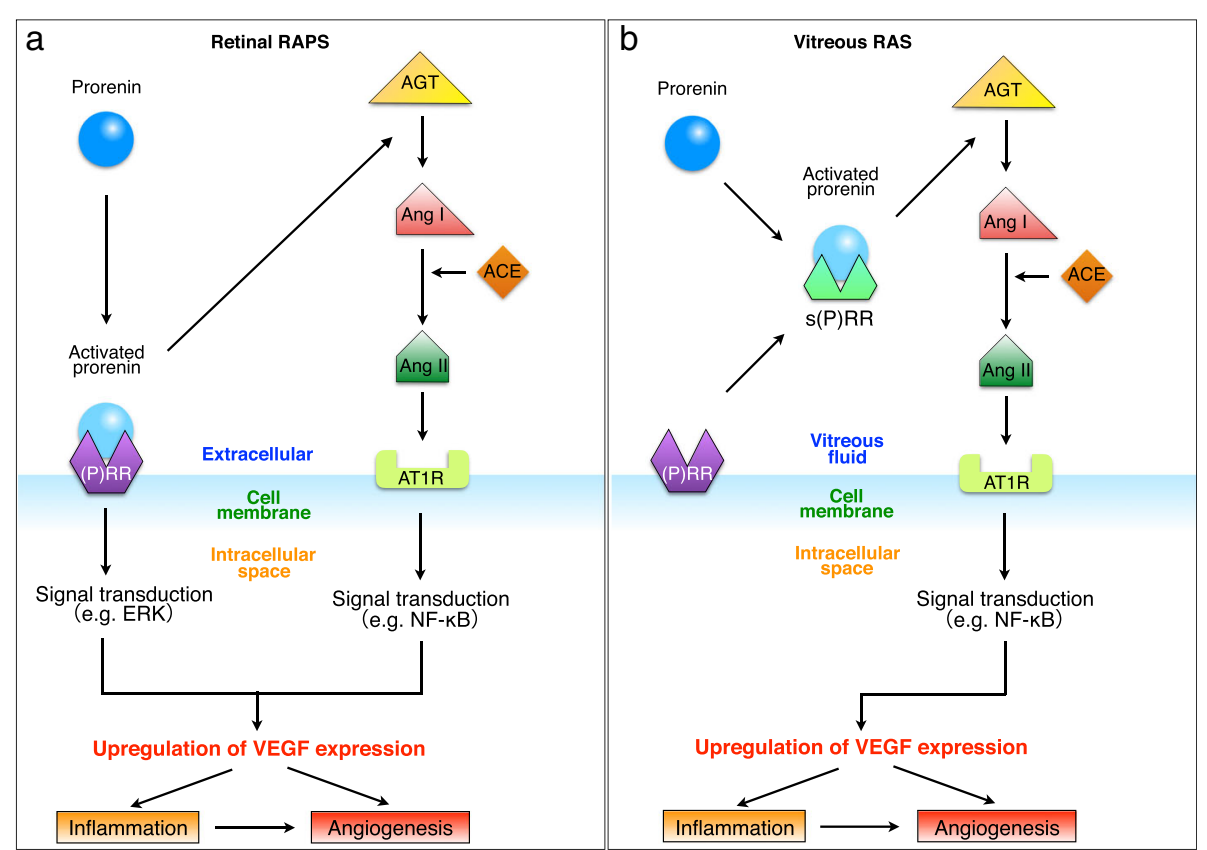

Fig. 1 A schema showing the significant involvement of retinal RAPS (a) and vitreous RAS (b) with the VEGF-driven pathogenesis of diabetic retinopathy. Vitreous RAS is caused by $s(P) R R$, whereas retinal RAPS depends on membrane-type (P)RR (modified from Kanda et al. [27]). ACE angiotensin-converting enzyme, AGT angiotensinogen, Ang I angiotensin I, Ang II angiotensin II, AT1R angiotensin II type 1 receptor, ERK extracellular signal-regulated kinase, NF-kB nuclear factor-kB, (P)RR (pro)renin receptor

The significance of the pathogenic system vitreous RAS may be attributed in part to a possibility of revising the current surgical indication and concept of vitrectomy for DR. In clinical setting, retinal surgeons remove the vitreous from PDR eyes because of (1) vitreous hemorrhage from newly formed vessels disturbing the visual axis and (2) tractional retinal detachment in which the retina is elevated by the vitreous that functions as the scaffold of the fibrovascular proliferative tissue originating from retinal vessels. These two major classic indications to the advanced stage have long been applied in terms of a mechanical or physical cue. In contrast, our data on vitreous renin activity indicate the possibility of the vitreous per se as the amplifier of the molecular pathogenesis of PDR. Retinal surgeons frequently encounter surgical cases where diabetic macular edema, a consequence of VEGF-induced vascular hyperpermeabiliy, is diminished soon after vitrectomy. This is explained at least in part by the pathological concept of vitreous RAS, the driving force of the downstream AT1R/nuclear factor-kB (NF-kB)/VEGF axis responsible for the pathogenesis of diabetic retinopathy (Fig. 1). It is reasonable, therefore, to think that the vitreous is not just the reservoir of detrimental cytokines but the factory of pathogenic RAS components. In this sense, vitrectomy procedure harbors a biochemical implication, which may expand the current surgical strategy to earlier intervention for broader indications to reduce the vitreous RAS- derived capability of producing VEGF and other several cytokines.

\section{Conclusions}

Our findings may not only lead to a new understanding of the molecular pathogenesis that implies a close link among the vitreous RAS, retinal RAPS, and VEGFinduced pathogenesis of diabetic retinopathy but also activate the clinical research in the surgical as well as medical point of view, thus contributing to further improvement of visual prognosis in patients with DR.

\section{Acknowledgements}

We thank Ikuyo Hirose (Hokkaido University) for their skillful technical assistance.

\section{Funding}

This work was supported in part by the Matching Program for Innovations in Future Drug Discovery and Medical Care, Takeda Science Foundation, and a grant-in-aid from the Ministry of Education, Science and Culture of Japan KAKENHI to A.K. (24791823, 16K11279) and S.I. (16H05484).

\section{Authors' contributions}

The authors equally contributed to the preparation of this review. All authors read and approved the final manuscript.

\section{Competing interests}

The authors declare that they have no competing interests.

\section{Consent for publication}

Not applicable.

Ethics approval and consent to participate Not applicable. 
Received: 18 July 2016 Accepted: 2 September 2016 Published online: 07 September 2016

\section{References}

1. Adamis AP, Miller JW, Bernal MT, D'Amico DJ, Folkman J, Yeo TK, Yeo KT. Increased vascular endothelial growth factor levels in the vitreous of eyes with proliferative diabetic retinopathy. Am J Ophthalmol. 1994;118:445-50.

2. Aiello LP, Avery RL, Arrigg PG, Keyt BA, Jampel HD, Shah ST, Pasquale LR, Thieme H, Iwamoto MA, Park JE, et al. Vascular endothelial growth factor in ocular fluid of patients with diabetic retinopathy and other retinal disorders. N Engl J Med. 1994;331:1480-7.

3. Malecaze F, Clamens S, Simorre-Pinatel V, Mathis A, Chollet P, Favard C, Bayard F, Plouet J. Detection of vascular endothelial growth factor messenger RNA and vascular endothelial growth factor-like activity in proliferative diabetic retinopathy. Arch Ophthalmol. 1994;112:1476-82.

4. Hurwitz H, Fehrenbacher L, Novotny W, Cartwright T, Hainsworth J, Heim W, Berlin J, Baron A, Griffing S, Holmgren E, et al. Bevacizumab plus irinotecan, fluorouracil, and leucovorin for metastatic colorectal cancer. N Engl J Med. 2004;350:2335-42.

5. Ishida S, Usui T, Yamashiro K, Kaji Y, Ahmed E, Carrasquillo KG, Amano S, Hida T, Oguchi Y, Adamis AP. VEGF164 is proinflammatory in the diabetic retina. Invest Ophthalmol Vis Sci. 2003:44:2155-62.

6. Ishida S, Usui T, Yamashiro K, Kaji Y, Amano S, Ogura Y, Hida T, Oguchi Y, Ambati J, Miller JW, et al. VEGF164-mediated inflammation is required for pathological, but not physiological, ischemia-induced retinal neovascularization. J Exp Med. 2003;198:483-9.

7. Usui T, Ishida S, Yamashiro K, Kaji Y, Poulaki V, Moore J, Moore T, Amano S, Horikawa Y, Dartt D, et al. VEGF164(165) as the pathological isoform: differential leukocyte and endothelial responses through VEGFR1 and VEGFR2. Invest Ophthalmol Vis Sci. 2004;45:368-74.

8. Paul M, Poyan Mehr A, Kreutz R. Physiology of local renin-angiotensin systems. Physiol Rev. 2006;86:747-803.

9. Ager El, Neo J, Christophi C. The renin-angiotensin system and malignancy. Carcinogenesis. 2008;29:1675-84.

10. Ramalho FS, Ramalho LN, Castro-e-Silva Junior O, Zucoloto S, Correa FM. Effect of angiotensin-converting enzyme inhibitors on liver regeneration in rats. Hepatogastroenterology. 2002:49:1347-51.

11. Yayama K, Miyagi R, Sugiyama K, Sugaya T, Fukamizu A, Okamoto H. Angiotensin II regulates liver regeneration via type 1 receptor following partial hepatectomy in mice. Biol Pharm Bull. 2008;31:1356-61.

12. Chaturvedi N, Sjolie AK, Stephenson JM, Abrahamian H, Keipes M, Castellarin A, Rogulja-Pepeonik Z, Fuller JH. Effect of lisinopril on progression of retinopathy in normotensive people with type 1 diabetes. The EUCLID study group. EURODIAB controlled trial of lisinopril in insulin-dependent diabetes mellitus. Lancet. 1998;351:28-31.

13. Chaturvedi N, Porta M, Klein R, Orchard T, Fuller J, Parving HH, Bilous R, Sjolie AK. Effect of candesartan on prevention (DIRECT-Prevent 1) and progression (DIRECT-Protect 1) of retinopathy in type 1 diabetes: randomised, placebo-controlled trials. Lancet. 2008;372:1394-402.

14. Sjolie AK, Klein R, Porta M, Orchard T, Fuller J, Parving HH, Bilous R, Chaturvedi $\mathrm{N}$. Effect of candesartan on progression and regression of retinopathy in type 2 diabetes (DIRECT-Protect 2): a randomised placebo-controlled trial. Lancet. 2008;372:1385-93.

15. Mauer M, Zinman B, Gardiner R, Suissa S, Sinaiko A, Strand T, Drummond K, Donnelly S, Goodyer P, Gubler MC, Klein R. Renal and retinal effects of enalapril and losartan in type 1 diabetes. N Engl J Med. 2009;361:40-51.

16. Nagai N, Izumi-Nagai K, Oike Y, Koto T, Satofuka S, Ozawa Y, Yamashiro K, Inoue M, Tsubota K, Umezawa K, Ishida S. Suppression of diabetes-induced retinal inflammation by blocking the angiotensin II type 1 receptor or its downstream nuclear factor-kappaB pathway. Invest Ophthalmol Vis Sci. 2007:48:4342-50.

17. Nagai N, Noda K, Urano T, Kubota Y, Shinoda H, Koto T, Shinoda K, Inoue M, Shiomi T, Ikeda E, et al. Selective suppression of pathologic, but not physiologic, retinal neovascularization by blocking the angiotensin II type 1 receptor. Invest Ophthalmol Vis Sci. 2005;46:1078-84.

18. Nagai N, Oike Y, Izumi-Nagai K, Urano T, Kubota Y, Noda K, Ozawa Y, Inoue M, Tsubota K, Suda T, Ishida S. Angiotensin II type 1 receptor-mediated inflammation is required for choroidal neovascularization. Arterioscler Thromb Vasc Biol. 2006;26:2252-9.

19. Satofuka S, Ichihara A, Nagai N, Koto T, Shinoda H, Noda K, Ozawa Y, Inoue $M$, Tsubota $K$, Itoh $H$, et al. Role of nonproteolytically activated prorenin in pathologic, but not physiologic, retinal neovascularization. Invest Ophthalmol Vis Sci. 2007:48:422-9.

20. Satofuka S, Ichihara A, Nagai N, Noda K, Ozawa Y, Fukamizu A, Tsubota K, Itoh $\mathrm{H}$, Oike $Y$, Ishida S. (Pro)renin receptor promotes choroidal neovascularization by activating its signal transduction and tissue renin-angiotensin system. Am J Pathol. 2008;173:1911-8.

21. Satofuka S, Ichihara A, Nagai N, Noda K, Ozawa Y, Fukamizu A, Tsubota K, Itoh $\mathrm{H}$, Oike $\mathrm{Y}$, Ishida $\mathrm{S}$. (Pro)renin receptor-mediated signal transduction and tissue renin-angiotensin system contribute to diabetes-induced retinal inflammation. Diabetes. 2009;58:1625-33.

22. Satofuka S, Ichihara A, Nagai N, Yamashiro K, Koto T, Shinoda H, Noda K, Ozawa $Y$, Inoue M, Tsubota K, et al. Suppression of ocular inflammation in endotoxin-induced uveitis by inhibiting nonproteolytic activation of prorenin. Invest Ophthalmol Vis Sci. 2006;47:2686-92.

23. Nabi AH, Kageshima A, Uddin MN, Nakagawa T, Park EY, Suzuki F. Binding properties of rat prorenin and renin to the recombinant rat renin/prorenin receptor prepared by a baculovirus expression system. Int J Mol Med. 2006;18:483-8.

24. Satofuka S, Kanda A, Ishida S. Receptor-associated prorenin system in the pathogenesis of retinal diseases. Front Biosci. 2012;4:1449-60.

25. Biswas KB, Nabi AN, Arai $Y$, Nakagawa T, Ebihara A, Ichihara A, Inagami T, Suzuki F. Qualitative and quantitative analyses of (pro)renin receptor in the medium of cultured human umbilical vein endothelial cells. Hypertens Res. 2010;34:735-9.

26. Kanda A, Noda K, Saito W, Ishida S. (Pro)renin receptor is associated with angiogenic activity in proliferative diabetic retinopathy. Diabetologia. 2012;55:3104-13.

27. Kanda A, Noda K, Saito W, Ishida S. Vitreous renin activity correlates with vascular endothelial growth factor in proliferative diabetic retinopathy. Br J Ophthalmol. 2013;97:666-8.

28. Ishizuka ET, Kanda A, Kase S, Noda K, Ishida S. Involvement of the receptor-associated prorenin system in the pathogenesis of human conjunctival lymphoma. Invest Ophthalmol Vis Sci. 2015;56:74-80.

29. Kanda A, Noda K, Ishida S. ATP6AP2/(pro)renin receptor contributes to glucose metabolism via stabilizing the pyruvate dehydrogenase E1 beta subunit. J Biol Chem. 2015;290:9690-700.

30. Kanda A, Noda K, Yuki K, Ozawa Y, Furukawa T, Ichihara A, Ishida S. Atp6ap2/(pro)renin receptor interacts with Par3 as a cell polarity determinant required for laminar formation during retinal development in mice. J Neurosci. 2013;33:19341-51.

31. Danser AH, van den Dorpel MA, Deinum J, Derkx FH, Franken AA, Peperkamp E, de Jong PT, Schalekamp MA. Renin, prorenin, and immunoreactive renin in vitreous fluid from eyes with and without diabetic retinopathy. J Clin Endocrinol Metab. 1989;68:160-7.

32. Funatsu $H$, Yamashita $H$, Nakanishi $Y$, Hori S. Angiotensin II and vascular endothelial growth factor in the vitreous fluid of patients with proliferative diabetic retinopathy. Br J Ophthalmol. 2002;86:311-5.

33. Gao BB, Chen X, Timothy N, Aiello LP, Feener EP. Characterization of the vitreous proteome in diabetes without diabetic retinopathy and diabetes with proliferative diabetic retinopathy. J Proteome Res. 2008;7:2516-25.

34. Gao BB, Clermont A, Rook S, Fonda SJ, Srinivasan VJ, Wojtkowski M, Fujimoto JG, Avery RL, Arrigg PG, Bursell SE, et al. Extracellular carbonic anhydrase mediates hemorrhagic retinal and cerebral vascular permeability through prekallikrein activation. Nat Med. 2007;13:181-8.

35. Cousin C, Bracquart D, Contrepas A, Corvol P, Muller L, Nguyen G. Soluble form of the (pro)renin receptor generated by intracellular cleavage by furin is secreted in plasma. Hypertension. 2009;53:1077-82.

36. Yoshikawa A, Aizaki Y, Kusano K, Kishi F, Susumu T, lida S, Ishiura S, Nishimura S, Shichiri M, Senbonmatsu T. The (pro)renin receptor is cleaved by ADAM19 in the Golgi leading to its secretion into extracellular space. Hypertens Res. 2011;34:599-605. 